\title{
Production and Characterization of Poly-3-hydroxybutyrate from Crude Glycerol by Bacillus sphaericus NII 0838 and Improving Its Thermal Properties by Blending with Other Polymers
}

\author{
Raveendran Sindhu ${ }^{1}$, Balakrishnan Ammu ${ }^{1}$, Parameswaran Binod ${ }^{1}$, Sreelatha K. Deepthi ${ }^{1}$, \\ K. B. Ramachandran ${ }^{2}$, Carlos Ricardo Soccol ${ }^{3}$ and Ashok Pandey ${ }^{1^{*}}$ \\ ${ }^{I}$ Biotechnology Division; National Institute for Interdisciplinary Science and Technology; CSIR; Trivandrum-695 \\ 019; India. ${ }^{2}$ Department of Biotechnology; Indian Institute of Technology; Chennai - 600 036; India. ${ }^{3}$ Divisão de \\ Engenharia de Bioprocessos e Biotecnologia; Universidade Federal do Paraná; 81531-970; Curitiba - Brasil
}

\begin{abstract}
The aim of this work was to study the production of poly-3-hydroxybutyrate (PHB) under nitrogen limited conditions by Bacillus sphaericus NII 0838 using crude glycerol from biodiesel industry as sole carbon source. Effect of various process parameters on PHB production such as glycerol concentration, inoculum size and pH of the medium were optimized. Characterization of extracted PHB was carried out by FT-IR, ${ }^{1} H$ and ${ }^{13} C$ NMR. Results showed that the bacterial culture accumulated about $31 \%$ PHB in crude glycerol medium. The extracted PHB was blended with other polymers to improve its physical characteristics. The thermal properties of the polymer like melting temperature $\left(T_{m}\right)$ and heat of fusion $(\Delta H f)$ were determined using DSC.
\end{abstract}

Key words: polyhydroxybutyrate, Bacillus sphaericus, polymer blends, crude glycerol, biodiesel industry

\section{INTRODUCTION}

Poly-3-hydroxybutyrate (PHB) is an intracellular lipid reserve material accumulated by many bacteria under conditions of nutrient stress, normally when an external carbon source is available but when concentrations of nutrients such as nitrogen, phosphorous or oxygen are limiting growth (Bitar and Underhill, 1990). It is an alternative source of plastics which has similar physical properties like polypropylene and it can be easily biodegradable aerobically and anaerobically (Arun et al., 2006). In PHB producing microbes, their synthesis takes place if a suitable carbon substrate is available in excess and cellular growth is limited by other nutrients like nitrogen or phosphate. At least 75 different genera of bacteria have been known to accumulate PHB as intracellular granules. Its production has most commonly been studied on micro-organisms belonging to the genera Alcaligenes, Azotobacter, Bacillus and Pseudomonas (Aysel et al., 2002).

The current cost of the PHB production is considerably more than that of the synthetic plastics. The costs of production depend on prices of feed stock for fermentation. Studies on process analysis and economic evaluation by Choi and Lee (1997) shown that PHB productivity, PHB

*Author for correspondence: pandey@niist.res.in 
content, PHB yield, and the cost of carbon substrate considerably affect the final price of PHB. Development of an efficient recovery method is also important to lower the price of PHB. The cost of raw materials can account for as much as $50 \%$ of the total operating cost as the production scale increases. Therefore, the cost of raw materials becomes very important to the overall economics of PHB production in a large scale. Since the cost of carbon source accounts for 70 to $80 \%$ of total raw material cost, the price of PHB can be significantly lowered if cheap carbon substrate can be used (Choi and Lee, 1997). In this case, it is necessary to find inexpensive carbon sources. Agriculture and its associated industries produce many feedstock and co-products that are attractive raw materials for use in microbial production of PHB. It is also necessary to take into account the fact that high-yield organisms have to tolerate relatively non-standardized raw or waste materials. From an ecological point of view, they are renewable and from an economic point of view, many of the co-products being studied are derived from surplus or low-cost processing streams.

The production of biodiesel generates significant quantities of co-product stream rich in glycerol. New uses for glycerol have been the subject of much research to alleviate a market glut of this commodity and to leverage the economics of biodiesel production. One potential use of glycerol is in industrial fermentation where it can be employed as a substrate for microbial growth and the biosynthesis of microbial products. For each 100 kilogram of biodiesel, 10 kilogram of crude glycerol is produced as byproduct. The utilization of crude glycerol will be of immense importance alleviating its disposal problem and producing a value added product. Its utilization in biodegradable polymer production will be attractive. The utilization of crude glycerol from biodiesel industry has been reported by several authors (Ashby et al., 2004; Borman and Roth, 1999; Koller et al., 2005; Mothes et al., 2007). However, significant decrease in PHB productivity and yields were reported.

The aim of the present study was to identify the microorganisms producing PHB and optimizing the fermentative production of PHB using crude glycerol from biodiesel industry as sole carbon source. The extracted PHB was used for the preparation of $\mathrm{PHB}$ polymer film and polymer blends. Characterizations of native PHB as well as blends were carried out by FTIR, DSC, ${ }^{1} \mathrm{H}-\mathrm{NMR}$ and ${ }^{13} \mathrm{C}$ - NMR analysis.

\section{MATERIALS AND METHODS}

\section{Chemicals and reagents}

Crude glycerol was obtained from Yantra Fintech India Pvt. Ltd, Chennai, India. Compositional analysis of crude glycerol showed the following components (\%, v/v) Glycerol-82; moisture-3.0; FFA-4.5; ash-6.0; ester-1.0; methanol-0.1; other organic matter-8.0. Crotonic acid and PHB standards were obtained from Sigma-Aldrich, India. All other chemicals were reagent grade procured from local vendors.

\section{Microorganisms and growth conditions}

All the microorganisms used in this study were maintained on nutrient agar slants. The inoculums were prepared in test tubes containing LB media and incubated at $30{ }^{\circ} \mathrm{C}$ for 24 hours on a rotary shaker at $250 \mathrm{rpm}$. The seed cultures $(1 \% \mathrm{v} / \mathrm{v})$ were transferred to $100 \mathrm{ml}$ of fermentation media as and when required.

\section{Primary screening of organisms for PHB production}

A preliminary screening of various organisms for PHB production was carried out by Nile blue staining techniques (Anthony and Holt, 1982). The cultures were grown in phosphorus and nitrogen limited condition for 48 hours. Smear was prepared and heat fixed on a microscopic slide and it was stained with $1 \%$ Nile blue. It was then incubated at $55^{\circ} \mathrm{C}$ for 10 minutes, destained using $8 \%$ acetic acid and observed using a microscope fitted with fluorescence filter at excitation wavelength at $390 \mathrm{~nm}$.

\section{Fermentative production of $\mathrm{PHB}$}

The five PHB producing strains, selected by preliminary screening by Nile blue staining method, were quantified for the PHB production in Phosphorus limited (P) and Nitrogen limited (N) condition. The composition of the $\mathrm{P}$ limited media includes crude glycerol - 10g/l; $\left(\mathrm{NH}_{4}\right)_{2} \mathrm{SO}_{4}-4 \mathrm{~g} / \mathrm{l}$; $\mathrm{MgSO}_{4} .7 \mathrm{H}_{2} \mathrm{O}-1.2 \mathrm{~g} / \mathrm{l}$; Citric Acid- $1.7 \mathrm{~g} / \mathrm{l}$; Trace Element Solution- $10 \mathrm{ml} / \mathrm{l}$. The N-limited media consists of $\left(\mathrm{NH}_{4}\right)_{2} \mathrm{SO}_{4}-2 \mathrm{~g} / \mathrm{l} ; \mathrm{KH}_{2} \mathrm{PO}_{4}-2 \mathrm{~g} / \mathrm{l}$; $\mathrm{MgSO}_{4} .7 \mathrm{H}_{2} \mathrm{O}-0.2 \mathrm{~g} / \mathrm{l} ; \mathrm{Na}_{2} \mathrm{HPO}_{4}-0.6 \mathrm{~g} / \mathrm{l}$; Yeast Extract $-0.2 \mathrm{~g} / \mathrm{l}$ and crude glycerol $-20 \mathrm{~g} / \mathrm{l}$. The 
composition of trace element solution were $\mathrm{FeSO}_{4} \cdot 7 \mathrm{H}_{2} \mathrm{O}-10 \mathrm{~g} / \mathrm{l} ; \mathrm{ZnSO}_{4} \cdot 7 \mathrm{H}_{2} \mathrm{O}-2.25 \mathrm{~g} / \mathrm{l}$; $\mathrm{CuSO}_{4} .5 \mathrm{H}_{2} \mathrm{O}-1 \mathrm{~g} / \mathrm{l} ; \mathrm{MnSO}_{4} .5 \mathrm{H}_{2} \mathrm{O}-0.5 \mathrm{~g} / \mathrm{l} ;$ $\mathrm{CaCl}_{2} .2 \mathrm{H}_{2} \mathrm{O}-0.2 \mathrm{~g} / \mathrm{l} ; \mathrm{Na}_{2} \mathrm{~B}_{4} \mathrm{O}_{7} .7 \mathrm{H}_{2} \mathrm{O}-0.23 \mathrm{~g} / \mathrm{l} ;$ $\left(\mathrm{NH}_{4}\right)_{8} \mathrm{Mo}_{7} \mathrm{O}_{24}-0.1 \mathrm{~g} / \mathrm{l}$ and $35 \% \mathrm{HCl}-10 \mathrm{ml} / \mathrm{l}$.

\section{PHB assay}

Assay of PHB was carried out by the method of Law and Slepecky (1961). The P and N limited media were inoculated with standard PHB producing strains and incubated for 48 hours. The media was centrifuged and the pellet lyophilized. The pellet was treated with $30 \%$ sodium hypochlorite and incubated at $37{ }^{\circ} \mathrm{C}$ for 30 minutes. The sample was centrifuged at $8,000 \mathrm{rpm}$ for 30 minutes and washed with distilled water, acetone, methanol and chloroform. The supernatant was collected and vapourized. It was further treated with concentrated $\mathrm{H}_{2} \mathrm{SO}_{4}$ and incubated at $100{ }^{\circ} \mathrm{C}$ for 10 minutes. Absorbance was taken at $235 \mathrm{~nm}$ using a UV-Visible spectrophotometer (Shimadzu UV-1601, Japan) with crotonic acid as standard.

\section{Optimization of process parameters}

Effects of glucose, commercial glycerol and crude glycerol from biodiesel industry on PHB production by Bacillus sphaericus NII 0838 were checked in $\mathrm{P}$ and $\mathrm{N}$ - limited medium. The effect of crude glycerol concentration on PHB production was carried out by growing the organism in different glycerol concentrations such as $0.5,1,2$, 3,4 and 5\% (v/v) in the $\mathrm{N}$ - limited media. The effect of the initial $\mathrm{pH}$ of the production medium on PHB production was carried out by growing $B$. sphaericus NII 0838 with $1 \%$ (v/v) glycerol concentration as sole carbon source in the $\mathrm{N}$ limit media at $\mathrm{pH} 4.0,5.0,6.0,7.0,8.0$ and 9.0 with $3 \%$ $(\mathrm{v} / \mathrm{v})$ inoculums size.

\section{Characterization of PHB}

Fourier Transform Infrared Spectroscopy (FTIR) The presence of different functional groups in PHB was checked by FTIR. Extracted PHB ( $2 \mathrm{mg}$ ) and standard PHB from Sigma $(2 \mathrm{mg}$ ) were dissolved in $500 \mu \mathrm{l}$ of chloroform and layered on $\mathrm{NaCl}$ crystal. After evaporation of chloroform, PHB polymer film was subjected to FTIR.

\section{Proton and carbon NMR}

The ${ }^{1} \mathrm{H}$ - NMR spectra was recorded at $30{ }^{\circ} \mathrm{C}$ with a Bruker Advance II $500 \mathrm{MHz}$ spectrometer equipped with ${ }^{1} \mathrm{H}$ and ${ }^{13} \mathrm{C}$ dual probe to study the structural elucidation. Proton spectra were recorded at $300.13 \mathrm{MHz}$ with a spectral width of $2,840 \mathrm{~Hz}$ over $16 \mathrm{~K}$ data points. A $66^{\circ}$ pulse angle was used. The ${ }^{13} \mathrm{C}$ - NMR spectrum was also recorded at at $30{ }^{\circ} \mathrm{C}$ with a Bruker Advance II 500 $\mathrm{MHz}$ spectrometer equipped with ${ }^{1} \mathrm{H}$ and ${ }^{13} \mathrm{C}$ dual probe to study the structural elucidation. $20 \mathrm{mg}$ of the standard and extracted PHB was dissolved in $\mathrm{CDCl}_{3}$ and subjected to analysis.

\section{Preparation of polymer blends}

Various polymer blends were prepared with PHB. The components in appropriate ratio were dissolved in hot chloroform $(15 \% \mathrm{w} / \mathrm{w})$ under stirring at $70^{\circ} \mathrm{C}$. The blend films were prepared by conventional solvent casting technique and the solvent was slowly evaporated at room temperature (Taweel et al., 2004).

\section{PHB-Poly lactic acid blends}

PHB and Poly Lactic acid (PLA) were mixed in different ratios $(w / w)$ of $18: 82$ and $67: 45$. The mixtures were then mixed with hot chloroform $(15 \% \mathrm{w} / \mathrm{w})$ and blend films were prepared by conventional solvent-casting technique from the chloroform solutions of PHB and PLA using glass beakers as casting surfaces (Yu et al., 2006).

\section{PHB- Thermoplastic starch blends}

Thermoplastic starch (TS) was obtained by mixing starch powder, water and glycerol in the composition 50:15:35 (w/v/v), respectively (Ramsay et al., 1993). The contents were mixed for 15-30 min. to obtain a paste. The paste was transformed into TS by heating at $100{ }^{\circ} \mathrm{C}$ in water bath with continuous stirring for $15 \mathrm{~min}$. This product so obtained was mixed with $\mathrm{PHB}$ in the ratios 58:52 (w/w) and 100:20 (w/w) and solvent cast films were obtained from chloroform.

\section{PHB-PLA-TS blends}

PHB, PLA and TS were mixed in 53: 39: 22 $(\mathrm{w} / \mathrm{w} / \mathrm{w})$ ratios. The blend films were prepared by solvent casting techniques as mentioned above.

\section{PHB-PEG-TS blends}

PHB, PEG and TS were mixed in a 52: 24: 24 (w/w/w) ratios and blend films were prepared as mentioned above. 


\section{PHB- starch blends}

PHB and starch were mixed in a 50: $50(\mathrm{w} / \mathrm{w})$ ratios and the blend films were prepared as mentioned above.

\section{Thermogravimetric analysis}

Thermogravimetry analysis (TGA) was performed on a Shimadzu instrument (Japan). The temperature was ramped at a heating rate of $10{ }^{\circ} \mathrm{C} / \mathrm{min}$ under nitrogen, to a temperature well above the degradation temperature of the polymers $\left(500{ }^{\circ} \mathrm{C}\right)$.

\section{Differential Scanning Calorimetry of polymer blends}

Differential Scanning Calorimetry (DSC) thermograms were recorded on a DSC instrument (Perkin Elmer Pyris 6), calibrated with indium (m.p. $156.61^{\circ} \mathrm{C} ; \Delta \mathrm{H}=28.54 \mathrm{~J} / \mathrm{g}$ ). The data was collected by heat and cool method. Samples of cast films weighed 5-10 mg were packed in aluminium pan and then heated from $20{ }^{\circ} \mathrm{C}$ to $200{ }^{\circ} \mathrm{C}$ at a scanning rate of $10{ }^{\circ} \mathrm{C}$ per minute under nitrogen atmosphere. The melting temperature $(\mathrm{Tm})$ and melting enthalpy $\left(\Delta \mathrm{H}_{\mathrm{f}}\right)$ were determined from DSC endothermal peaks. After one minute annealing, the sample was cooled to $20^{\circ} \mathrm{C}$.

The crystallinity $(\mathrm{Xc})$ of $\mathrm{PHB}$ in the blends is calculated as per equation given below.

$\mathrm{Xc}=\Delta \mathrm{H}_{\mathrm{f}} * 100 / \Delta \mathrm{H}_{\mathrm{o}} * \mathrm{~W}$

where,

$\Delta \mathrm{H}_{\mathrm{f}}=$ melting enthalpy of the sample $(\mathrm{J} / \mathrm{g})$.

$\Delta \mathrm{H}_{\mathrm{o}}=$ melting enthalpy of the $100 \%$ crystalline PHB which is assumed to be $146 \mathrm{~J} / \mathrm{g}$

$\mathrm{w}$ is the weight fraction of PHB in the sample.

\section{RESULTS}

\section{Screening of PHB producing microorganisms}

The preliminary screening of various microorganisms for PHB production by Nile blue staining resulted five bacterial strains supposed to be the potent PHB producers, as they showed fluorescence in presence of UV light (Fig. 1).
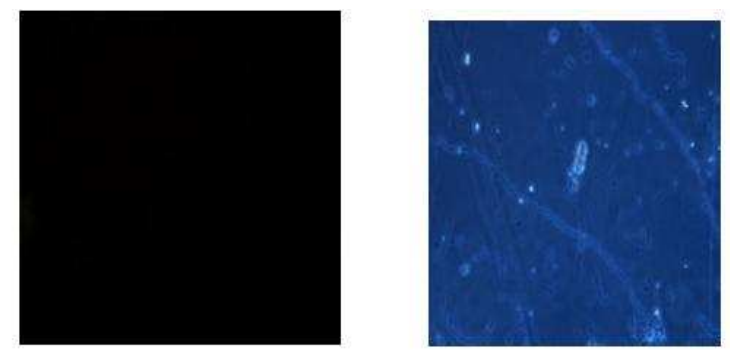

Control - E.coli

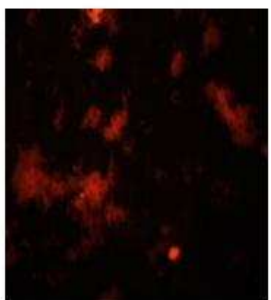

B. firmus NII 0830

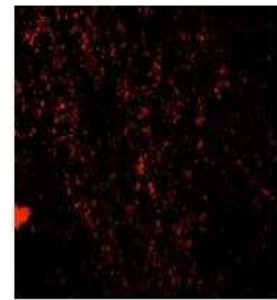

B. Finutus NII 0829

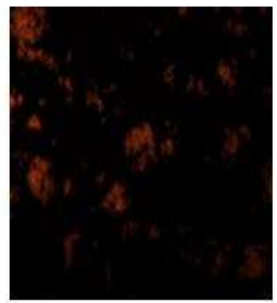

P.putida NII 0914

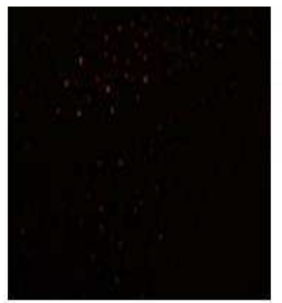

A. latus NII 0825

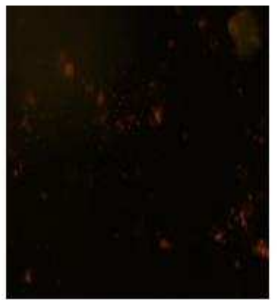

B.sphtaericus NII 0838

Figure 1 - Screening of various microorganisms for PHB production by Nile blue staining. 
These five strains were Bacillus firmus NII 0830, Bacillus firmus NII 0829, Pseudomonas putida NII 0914, Alcaligens latus NII 0825 and Bacillus sphaericus NII 0838. Bright orange fluorescing PHB granules were more prominent in Bacillus sphaericus NII 0838. The Nile blue stain binds specifically to PHB granules and they fluoresce with orange color under excitation wavelength of $390 \mathrm{~nm}$ (Spiekermann et al., 1999). The N- limit media showed more number of PHB granules than the P- limit media. The reports says that this viable-colony staining method was in particular applicable to gram-negative bacteria and it was less suitable for discriminating between PHAnegative and PHA-positive strains of grampositive bacteria such as Bacillus megaterium or Rhodococcus ruber (Spiekermann et al., 1999). But our studies show the presence of PHB in all the five positive strains and it was confirmed by FTIR and NMR analysis. Our studies indicate that this staining method could be used for the preliminary screening of PHB producing bacterial strains and these strains can be further evaluated for PHB by fermentation techniques. This will save time by avoiding screening of non-PHB producing strains by fermentation methods.

\section{Fermentative production of PHB}

The preliminary screening of various bacteria by Nile blue staining method indicated that Bacillus sphaericus NII 0838 was a potent PHB producer. So this strain was selected for further experiments. The fermentative production of PHB was evaluated with three different carbon sources, such as glucose, commercial glycerol and crude glycerol from biodiesel industry, in both $\mathrm{N}$ and $\mathrm{P}-$ limited media. The organism is flexible in utilizing different sources of carbon for its growth and PHB accumulation. Among the different carbon sources tested glucose is easily utilized for maximum PHB and biomass production followed by crude glycerol and commercial glycerol. The PHB production by using crude glycerol as carbon source was greater than commercial glycerol (Fig. 2). The total PHB accumulation was found to be slightly greater in the P- limit media than the $\mathrm{N}$ limit media. But the biomass produced in the Nlimit media was much greater than the P- limit media so, the total PHB yield per cell biomass was greater in the $\mathrm{N}$ - limit media. Therefore, the $\mathrm{N}$ limit media was selected for the further optimization of various other factors.

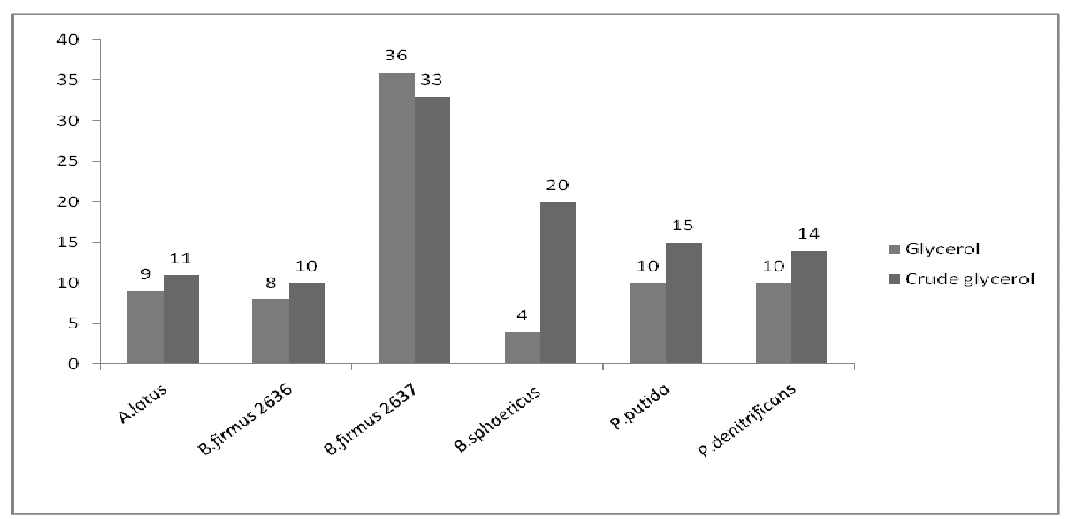

Figure 2 - Comparison of different carbon sources on PHB production in $\mathrm{N}$ and $\mathrm{P}$ limited conditions.

Optimization of crude glycerol concentration, inoculums size and initial media $\mathbf{p H}$

When $\mathrm{N}$ - limited medium were used with different crude glycerol concentrations as sole carbon source ranging from $1-5 \%(\mathrm{v} / \mathrm{v})$, maximum PHB yield was obtained at $1 \%$ glycerol concentration (Data not shown). This might be attributed to substrate inhibition at higher concentration. Effect of inoculums size on PHB production by Bacillus sphaericus NII 0838 revealed that inoculums concentration of $3 \%(\mathrm{v} / \mathrm{v})$ was optimum for maximum accumulation of PHB (data not shown). Decrease in PHB production with increase in the inoculums size beyond $3 \%(\mathrm{v} / \mathrm{v})$ is indicative of the critical role of inoculums for PHB production. The most widely accepted strategy for the PHB production is that initially very high cell densities are achieved and then the limiting conditions are developed to trigger the PHB accumulation. Effect of initial $\mathrm{pH}$ on $\mathrm{PHB}$ production by Bacillus 
sphaericus NII 0838 showed that $\mathrm{pH} 7.0$ was optimum for maximum PHB accumulation.

\section{Characterization of PHB produced from Bacillus sphaericus NII 0838: Fourier Transform Infrared Spectroscopy}

FTIR spectra of the extracted polymer show peaks at $1726.29 \mathrm{~cm}^{-1}$ and $1276.88 \mathrm{~cm}^{-1}$ corresponding to specific rotations around carbon atoms specific to certain functional groups (Fig. 3). The peak at $1726.29 \mathrm{~cm}^{-1}$ corresponds to $\mathrm{C}=\mathrm{O}$ stretch of the ester group present in the molecular chain of highly ordered crystalline structure (Padermshoke et al., 2004). The peak at $1276.88 \mathrm{~cm}^{-1}$ corresponds to $-\mathrm{CH}$ group. These peaks are corresponding to the peaks obtained for the standard PHB (Sigma) at $1728 \mathrm{~cm}^{-1}$ and $1282 \mathrm{~cm}^{-1}$ confirming that the extracted polymer is PHB.

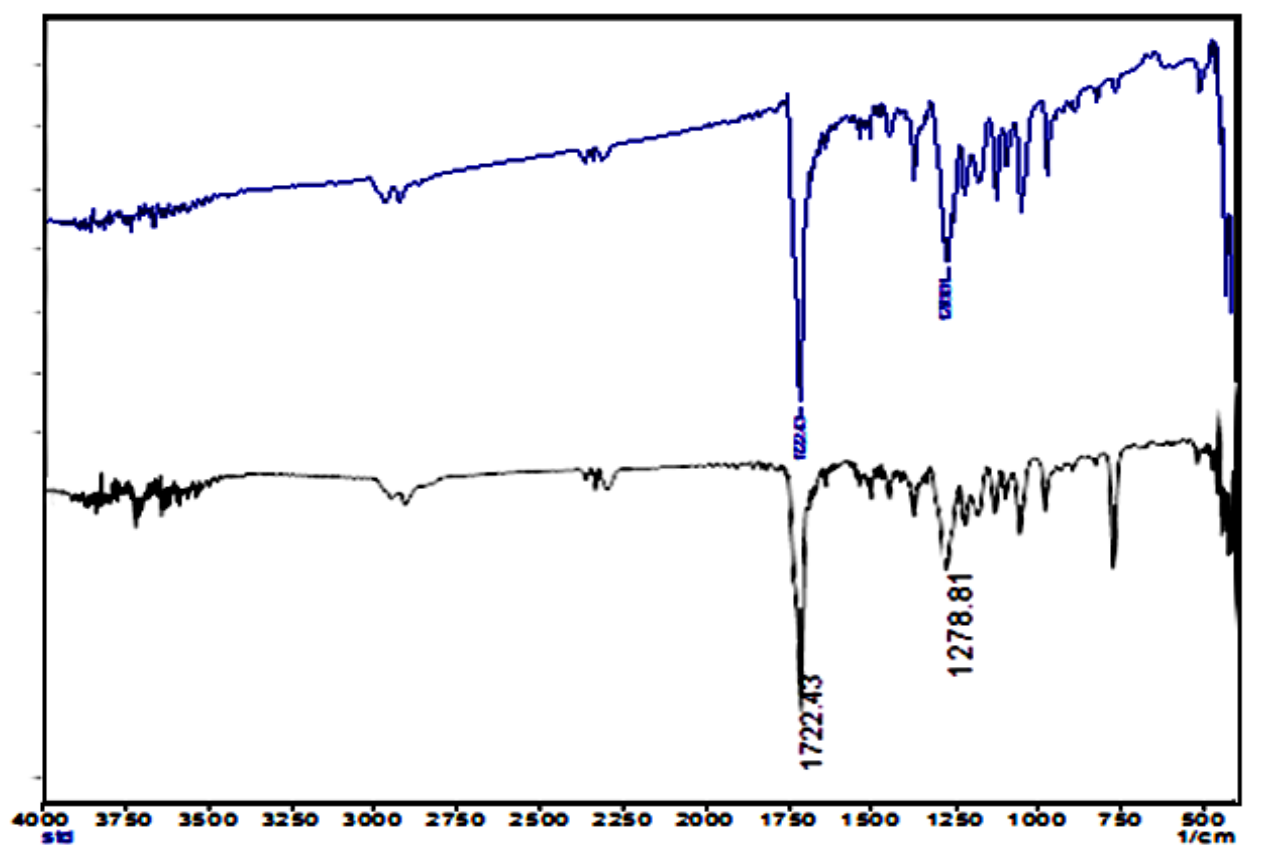

Figure 3 - FTIR spectra of PHB (Sigma) (Above) and extracted PHB (below).

\section{NMR analysis}

The ${ }^{1} \mathrm{H}$ NMR spectra obtained from extracted PHB from Bacillus sphaericus NII 0838 is compared with the commercial PHB (Sigma-Aldrich Chemicals, USA). Both spectra were found to match perfectly with each other (Fig. 4). The peaks observed in the spectra coincide, corresponding to the different types of carbon atoms in the PHB structure. The spectrum shows a doublet at $1.29 \mathrm{ppm}$ which is attributed to the methyl group coupled to one proton. The doublet of quadruplet at $2.57 \mathrm{ppm}$ is attributed to the methylene group adjacent to an asymmetric carbon atom bearing a single atom. The multiplet at $5.27 \mathrm{ppm}$ is characteristic of methylene group. Two other signals are observed, a broad one at 1.56 ppm which is due to water and another one at $7.25 \mathrm{ppm}$ attributed to the solvent used i.e. chloroform. Identical observations were earlier reported by (Bonthrone et al., 1992; Jan et al., 1996).

${ }^{13} \mathrm{C}$ NMR analysis also confirmed the structure of PHB polymer extracted from B. sphaericus NII 0838. The chemical shift signals of ${ }^{13} \mathrm{C}$ NMR spectrum obtained in the present work and the commercial PHB were identical to the ${ }^{13} \mathrm{C}$ NMR spectra of the PHB reported previously (Fabiane et al., 2007). The four peaks were assignable to the methyl (CH3, 19.7ppm), methylene ( $\mathrm{CH} 2$, 40.66ppm), methane ( $\mathrm{CH}, 67.6 \mathrm{ppm})$ and carbonyl $(\mathrm{C}=\mathrm{O}, 169.1 \mathrm{ppm})$ carbon resonance of $\mathrm{PHB}$ (Table 1). 


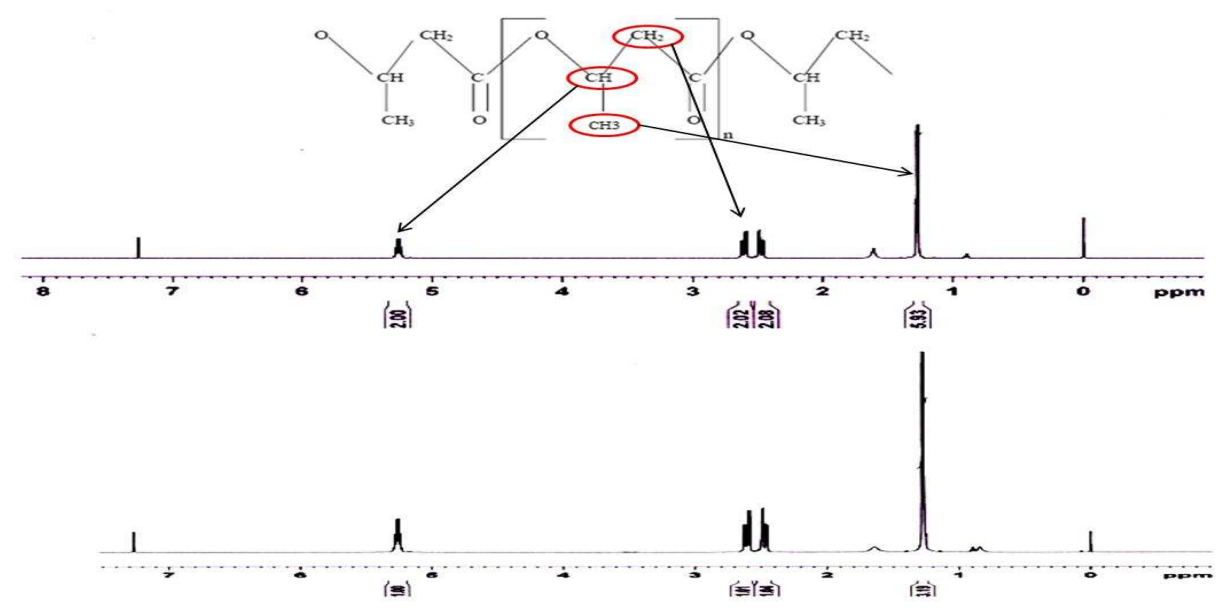

Figure $4-{ }^{1}$ H NMR spectra of PHB from Sigma (above) and extracted PHB (below).

Table 1 - Chemical shift signals of extracted PHB and PHB from sigma and compared with the literature

\begin{tabular}{llll}
\hline C atom & PHB extracted & PHB commercial & PHB (Fabiane et al., 2007) \\
\hline CH3 & 19.74 & 19.76 & 19.65 \\
CH2 & 40.76 & 40.78 & 40.66 \\
CH & 67.63 & 67.61 & 67.48 \\
C=0 & 169.21 & 169.15 & 169.03 \\
\hline
\end{tabular}

\section{Polymer blend studies}

The PHB blend produced was found to be brittle and breaks easily. Blending PHB with other polymers is an economic way to improve its mechanical properties. To this effect PHB were blended with thermo stable starch, poly lactic acid, polyethylene glycol and starch. The surface morphology of each blend was different from the other. They differed in their transparency and opacity. PHB and starch was not completely miscible and the blend showed insoluble particle aggregation on the surface. PHB and PLA were completely miscible but were found to be more brittle than PHB and TS. The possible advantage of using TS containing PHB as compared with native starch granules lies in that it can be deformed and distributed in the blending process. In addition, this type of TS can be reprocessed at elevated temperature, as it retains its flexibility (Godbole et al., 2003).

\section{Thermogravimetric analysis}

Figure 5 shows the TGA thermograms of PHB biofilm and its blend. The thermal degradation of extracted PHB proceeds by a one-step process with a maximum decomposition temperature at $291{ }^{\circ} \mathrm{C}$. This thermal degradation at maximum decomposition temperature of approximately $300{ }^{\circ} \mathrm{C}$ is mainly associated with the ester cleavage of PHB component by $\beta$-elimination reaction (Choi et al., 2003). However, the thermal decomposition patterns of blends followed a considerably different pattern from the single-step reaction of the PHB. Maximum decomposition temperature also increased from $291{ }^{\circ} \mathrm{C}$ to $500{ }^{\circ} \mathrm{C}$. The temperature of $291{ }^{\circ} \mathrm{C}$ was found to be the maximum decomposition temperature for biofilm made with extracted PHB and it was almost same for standard PHB from Sigma $\left(302{ }^{\circ} \mathrm{C}\right)$. The decomposition temperature for all the blends made in this experiment was beyond $300{ }^{\circ} \mathrm{C}$. The residual weight of different blends at temperature beyond $300^{\circ} \mathrm{C}$ is shown in Table 2 . 


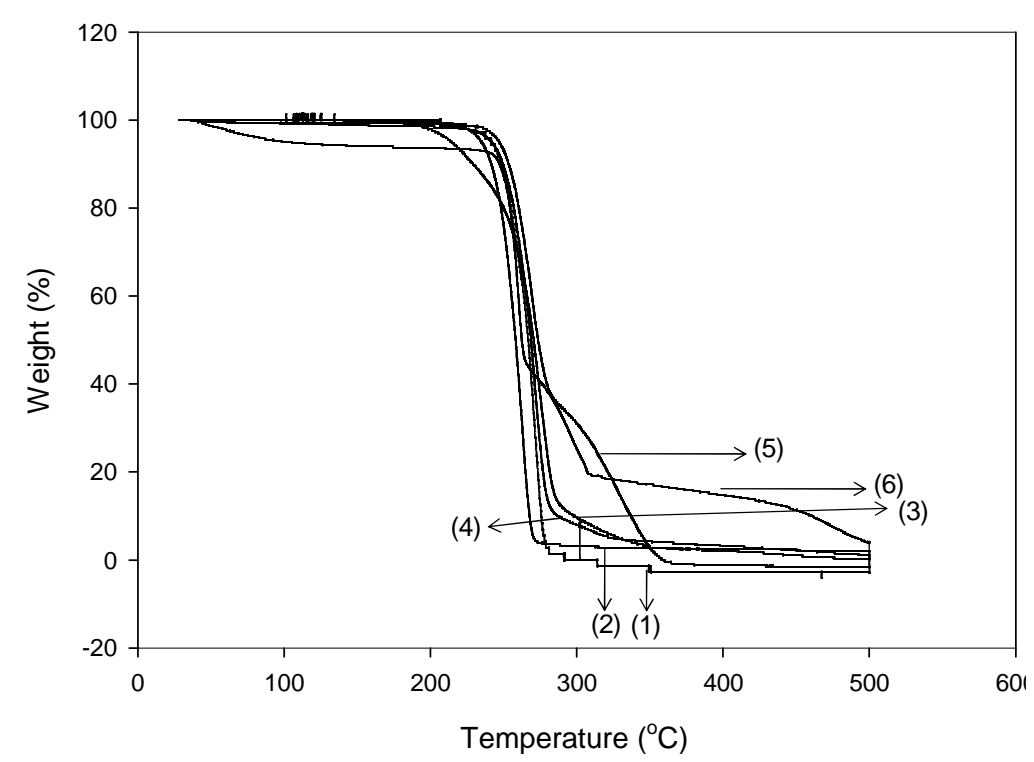

Figure 5 - TGA curves of extracted PHB and PHB blends.
(1) Film made from extracted PHB
(2) Film made from Sigma PHB
(3) PHB-PLA-TS
(4) PHB-TS
(5) PHB-PEG-TS
(6) PHB-Starch

Table 2- Initial and maximum decomposition temperatures evaluated from TGA.

\begin{tabular}{llll}
\hline Biofilm & $\operatorname{Ti}\left({ }^{\circ} \mathrm{C}\right)^{*}$ & $\operatorname{Tmax}\left({ }^{\circ} \mathrm{C}\right)$ & Residual weight $(\%)$ at $300{ }^{\circ} \mathrm{C}$ \\
\hline PHB from B. sphaericus & 241 & 291 & 0 \\
PHB (Sigma) & 234 & 302 & 0 \\
PHB-PLA-TS & 213 & 500 & 9.4 \\
PHB-TS & 241 & 500 & 7.9 \\
PHB-PEG-TS & 246 & 500 & 30.9 \\
PHB-Starch & 98 & 358 & 24.9 \\
\hline
\end{tabular}

*Values determined at a $5 \%$ weight loss on the TGA thermograms.

\section{Differential scanning calorimetry}

Non - isothermal DSC studies of PHB and its blends were carried out in order to have an understanding of the effect on crystallinity of PHB. The PHB extracted, PHB Sigma and PHBTS showed two endothermal peaks in between 140 and $200{ }^{\circ} \mathrm{C}$ (Fig. 6). The peak at the higher temperature is attributed to the melting of the crystalline film. Another endothermal peak appearing at a lower temperature is also clearly shown which is probably due to the melting of the imperfect crystals formed during the sample preparation.

The melting enthalpy $\left(\Delta \mathrm{H}_{\mathrm{f}}\right)$ was obtained from the area of the two endothermal peaks. The crystallinity degree $(\mathrm{Xc})$ was calculated based on the melting enthalpy of $146 \mathrm{~J} / \mathrm{g}$ of $100 \%$ crystalline PHB. Intensified cold crystallization of the blend samples at about $65{ }^{\circ} \mathrm{C}$ may be the results from the inability of all the crystallizable chains to crystallize completely during the cooling cycles. When the PHB content was lowered and the TS and PLA content increased, the PHB microcrystal's or ordered chains could be more easily removed to pack into a denser or perfect crystalline structure as PHB is still a highly crystalline polymer with low crystallization rate. The melting temperature $(\mathrm{Tm})$ for standard PHB, the extracted PHB, PHB-TS blends were almost same and for PHB - PLA blend is slightly higher. The enthalpy of melting ( $\Delta \mathrm{Hf}$ ) is $36.5 \mathrm{~J} / \mathrm{g}$ for standard PHB and for extracted one is $29.09 \mathrm{~J} / \mathrm{g}$ (Table 3). 

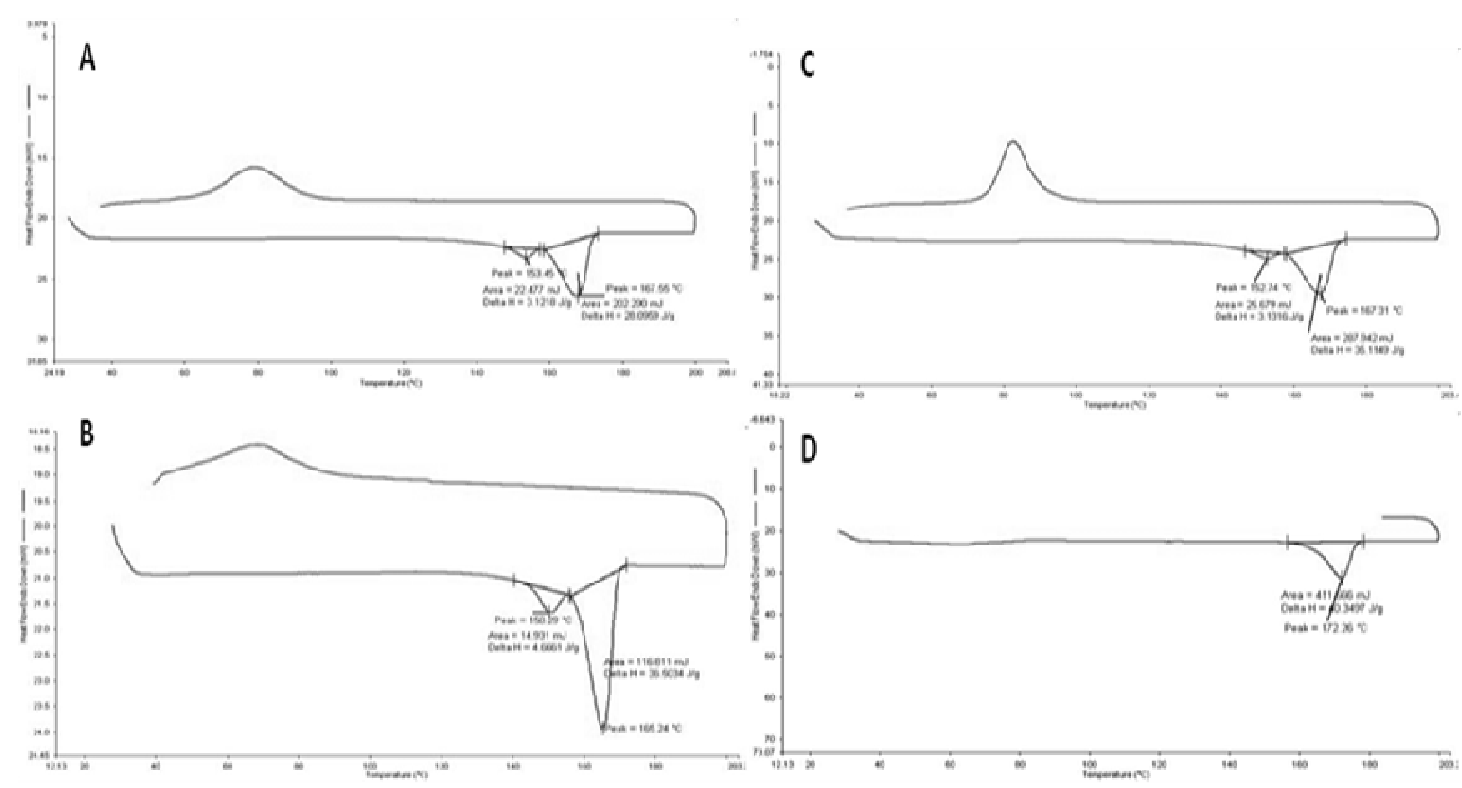

Figure 6 - DSC thermograms of extracted PHB and PHB blends A: PHB extracted; B: PHB from sigma; C: PHB-TS blend; D: PHB-PLA blend.

Table 3 - DSC results of the extracted PHB and its blends.

\begin{tabular}{llll}
\hline PHB $\%(w / w)$ & $\operatorname{Tm}\left({ }^{\circ} \mathrm{C}\right)$ & $\Delta H f(J / g)$ & $\mathrm{Xc}(\%)$ \\
\hline PHB extract & 165.24 & 36.50 & 50 \\
PHB Sigma & 167.55 & 28.09 & 38 \\
PHB-TS & 167.31 & 35.11 & 46 \\
PHB-PLA & 172.26 & 40.34 & 41 \\
\hline
\end{tabular}

\section{DISCUSSION}

The harmful effects of synthetic plastics in the environment have been of increasing concern for the last several years. This ecological awareness impelled development of new, eco-friendly materials, especially for single-use plastic items. Polyhydroxybutyrate (PHB) is an alternative because it has similar biodegradability characteristics to those of conventional thermoplastics (Baltieri et al., 2003). However, use of PHB is limited because of its thermal instability, excessive brittleness, and high production cost compared with synthetic plastics (El-Hadi et al., 2002). Blending of PHB with other bio-degradable polymers appears a promising solution to these problems.

Two different cultivation methods can be employed for efficient production of PHB by different bacteria (Lee, 1996). Many bacteria including Alcaligenes eutrophus, methylotrophs, and Pseudomonas oleovorans synthesize PHAs under the limitation of a nutritional element such as $\mathrm{N}, \mathrm{P}, \mathrm{Mg}, \mathrm{K}, \mathrm{O}$, or $\mathrm{S}$ in the presence of excess carbon source. For the cultivation of these bacteria, two-step cultivation method is employed. Cells are first grown without nutrient limitation and then nutrient limitation is applied for PHA synthesis. The choice of limiting nutrient as well as the time point of applying nutrient limitation can significantly affect polymer production (Choi and Lee, 1997). However, some bacteria such as Alcaligenes latus, Azotobacter vinelandii, and recombinant $E$. coli do not require nutrient limitation for the synthesis of PHAs, and can accumulate PHAs during growth. For these bacteria, the nutrient feeding strategy is most important for the success of fermentation and should be optimized for each bacterium (Lee and Chang, 1995).

Borman and Roth (1999) used Methylobacterium rhodesianum to synthesize PHB at a product yield of $10.5 \mathrm{~g}$ polymer $\mathrm{l}^{-1}$ culture in a medium containing glycerol $(50 \%)$ and casein peptone as carbon and nitrogen sources, respectively. A similar experiment with Ralstonia eutropha DSM 
11348 yielded up to 15 and $17.6 \mathrm{~g}$ PHB $\mathrm{l}^{-1}$ of product with glycerol as the carbon source and casein peptone or Casamino acids as the nitrogen source. Ashby et al (2005) investigated the synthesis of PHB from glycerol in a chemically defined medium using Pseudomonas oleovorans reported an yield of $0.97 \mathrm{~g}$ polymer $1^{-1}$ in $5 \%$ glycerol medium in shake-flask cultures. A systematic study further showed that increasing the concentration of glycerol in the medium resulted in the synthesis of lower molecularweight PHB due to glycerol end-capping, a finding that is certain to have an important implication when using biodiesel-derived glycerol co-product streams to produce PHA. The actual use of a glycerol-rich biodiesel co-product stream for short chain length PHA production was reported by Koller et al (2005). These investigators showed that an unidentified osmophilic organism could produce PHB-co-poly hydroxyvalerate from the glycerol liquid phase from biodiesel production at a yield of $16.2 \mathrm{~g}$ polymer $\mathrm{l}^{-1}$ without the addition of an odd-number fatty acid precursor as typically required in other fermentation systems. These authors also described a decrease in molecular weight of the polymer as a result of using glycerolcontaining biodiesel co-product stream as a carbon source (Solaiman et al., 2006). In a companion study to their earlier work that used pure glycerol, (Ashby et al., 2004) reported the use of a well characterized biodiesel co-product stream containing $34 \%$ glycerol as the sole carbon source in a chemically defined basal medium to synthesize PHB by shake-flask cultures of $P$. oleovorans NRRL B-14682. Again, a decrease in the molecular weight of the polymer was observed with an increase of concentration of the glycerol biodiesel co-product stream in the culture medium. The present study shows that there is a wide possibility for using the crude glycerol byproduct from biodiesel industry for environmentally friendly bio-plastics production. The strain Bacillus sphaericus NII 0838 produced $31 \%$ PHB in $\mathrm{N}$-limited medium using crude glycerol as sole carbon source. The yield of PHB on particular carbon source is an important parameter in the microbial production of PHB. It is dependent on the cellular PHB content, since lower the amount of PHB in the cell the more carbon source is wasted on the residual biomass. In addition the
PHB content is also a key factor in further downstream processing costs.

The DSC results showed higher crystalline degree for pure PHB (50\%) when compared to PHB blends. The crystalline degrees of PHB in all the blends were maintained between $41 \%$ and $46 \%$. The lower crystalline degree and higher Tm of blends resulted from better plasticizing effect which depresses the crystallization of PHB and pushes the already formed microcrystals or ordered chains to pack into more perfect structures in the blends. An identical result was earlier reported by $\mathrm{Xu}$ et al, (2006) for PHB blends with dendrimers. The less compact structure would enhance the molecular entanglement and the molecular penetrating between TS/PEG and PHB. This interaction would suppress the crystallization of PHB which in turn decrease the degree of crystallinity. The intermolecular interactions between the PHB and the blending polymer, would lead to plasticizing or antiplasticizing effect depends on which is stronger.

The melting points of all the films ranged between 165 and $172{ }^{\circ} \mathrm{C}$. This indicates that there is no shift in the melting point of the polyesters suggesting that there is no interaction between the polymers. Identical results were earlier reported by Godbole et al, (2003).

$\mathrm{Xu}$ et al, 2006 carried out blending of PHB with dendrimers. The TGA results conclude that including dendrimers could retard the decomposition of PHB and enhance the thermal stability. Identical observations were reported by Choi et al, 2003 who prepared PHB with EPB blends. The blends showed a higher thermal stability. Parra et al, 2006 reported PHB blend preparation with PEG. It showed improved properties.

The results indicate that blending of PHB with other polymers could be advantageous for cost reduction with improved properties when compared to native PHB. PHB is very brittle and has low melting temperature. Thus the chemical structure of the polymer was changed by blending it with other polymers to improve its physical characteristics thus widening range of application of PHB. Polymer blending offers interesting possibilities of preparing inexpensive biodegradable materials with useful mechanical properties. 


\section{ACKNOWLEDGEMENTS}

The authors are grateful to Department of Biotechnology, Government of India and Council of Scientific and Industrial Research (CSIR), New Delhi for financial support.

\section{REFERENCES}

Anthony, O.G. and Holt, J.G. (1982), Nile blue A as a Fluorescent Stain for Poly-3-Hydroxybutyrate. Appl. Environ. Microbiol., 44, 238-241.

Arun, A.; Murrugappan, R.; Ravindran, A.D.D.; Veeramanikandan, V. and Balaji, S. (2006). Utilization of various industrial wastes for the production of poly-beta-hydroxy butyrate (PHB) by Alcaligenes eutrophus. Afr. J. Biotechnol., 5, 15241527.

Ashby, R.D.; Solaiman, D.K.Y. and Foglia, T.A. (2004). Bacterial Poly(hydroxyalkanoate) Polymer Production from the Biodiesel Co-product Stream. $J$ Polym. Environ., 12, 105-112.

Ashby, R.D.; Solaiman, D.K.Y. and Foglia, T.A. (2005). Synthesis of short-/medium-chain-length poly(hydroxyalkanoate) blends by mixed culture fermentation of glycerol. Biomacromolecules, $\mathbf{6}$, 2106-2112.

Aysel, U.; Sahin, N. and Beyatli, Y. (2002). Accumulation of Poly- $\beta$-Hydroxybutyrate in Streptomyces Species during Growth with Different Nitrogen Sources. Turk. J. Biol., 26, 171-174.

Baltieri, R.C.; Mei, L.H.I. and Bartoli, J. (2003). Study of the influence of plasticizers on the thermal and mechanical properties of poly(3-hydroxybutyrate) compounds. Macromol. Symp. , 197, 33-44.

Bitar, A. and Underhill, S. (1990). Effect of ammonium supplementation on production of Poly $\beta$ - hydroxybutyric acid by Alcaligenes eutrophus in batch culture. Biotechnol. Lett., 12, 563-568.

Bonthrone, K..M.; Clauss, J.; Horowitz, D.M.; Hunter, B.K. and Sanders, J.K..M (1992). The biological and physical chemistry of polyhydroxyalkanoates as seen by NMR spectroscopy. FEMS Microbiol. Rev., 103, 269-278.

Borman, E.J. and Roth, M. (1999). The production of polyhydroxybutyrate by Methylobacterium rhodesianum and Ralstonia eutropha in media containing glycerol and casein hydrolysates. Biotechnol. Lett., 21, 1059-1063.

Choi, J.I. and Lee, S.Y. (1997). Process analysis and economic evaluation for poly (3-hydroxybutyrate) production by fermentation. Bioprocess Eng., 17, 335-342.
Choi, J.Y.; Lee, J.K.; You, Y. and Park, W.H. (2003). Epoxidized Polybutadiene as a Thermal Stabilizer for Poly(3-hydroxybutyrate). II. Thermal Stabilization of Poly(3-hydroxybutyrate) by Epoxidized Polybutadiene. Fiber. Polym., 4, 195-198.

El-Hadi, A.; Schnabel, R.; Straube, E.; Müller, G. and Henning, S. (2002). Correlation between degree of crystallinity, morphology, glass temperature, mechanical properties and biodegradation of poly (3hydroxyalkanoate) PHAs and their blends. Polym.. Test., 212, 665-674.

Fabiane, C.O.; Marcos, L.D.; Leda, R.C. and Denise, M.G.F. (2007). Characterization of Poly(3hydroxybutyrate) produced by Cupriavidis necator in solid state fermentation. Bioresource Technol., 98, 633-638.

Godbole, S.; Gote, S.; Latkar, M. and Chakrabarti, T. (2003). Preparation and characterization of biodegradable poly-3-hydroxybutyrate-starch blend films. Bioresource Technol, 86, 33-37.

Jan, S.; Roblot, C.; Courtois, J.; Courtois, B.; Barbotin, J.N. and Shguin, J.P. (1996). ${ }^{\text {l} H ~ N M R ~ s p e c t r o s c o p i c ~}$ determination of poly 3-hydroxybutyrate extracted from microbial biomass. Enzyme Microb.Technol. 18, 195-201.

Koller, M.; Bona, R.; Braunegg, G.; Hermann, C.;Horvat, P.; Kroutil, M.; Martinz, J.; Neto, J.; Pereira, L. and Varila, P. (2005). Production of polyhydroxyalkanoates from agricultural waste and surplus materials. Biomacromolecules, 6, 561-565.

Law, J.H. and Slepecky, R.A. (1961). Assay of poly $-\beta$ hydroxyl butyric acid. J. Bacteriol., 82, 33-36.

Lee, S.Y. (1996). Plastic bacteria? Progress and prospects for polyhydroxyalkanoate production in bacteria. Trends Biotechnol., 14, 98-105.

Lee, S.Y. and Chang, H.N. (1995). Production of polyhydroxyalkanoic acid. Adv. Biochem. Eng. Biotechnol., 52, 27-58.

Mothes, G.; Schnorpfeil, C. and Ackermann, J.U. (2007). Production of PHB from Crude Glycerol. Eng Life Sci., 7, 475-479.

Padermshoke, A.; Katsumoto, Y.; Sato, H.; Ekgasit, S. and Noda, I. (2004). Surface melting and crystallization behavior of polyhydroxyalkanoates studied by attenuated total reflection infrared spectroscopy. Polymer 45, 6547-6554.

Parra, D.F; Fosaro, J; Gaboardi, F and Rosa, D.S.(2006). Influence of PEG on mechanical, morphological, physicochemical and biodegradation properties of PHB. Degrad.Stabil. 91, 1954 - 1959.

Ramsay, B.A.; Langlade, V.; Carreaus, P.J. and Ramsay, J.A. (1993). Biodegradability and Mechanical Properties of (PHB-co-HV) - starch blends. Appl. Environ. Microbiol., 59, 1242-1246. 
Solaiman, D.K.Y.; Ashby, R.D.; Foglia, T.A. and Marmer, W.N. (2006). Conversion of agricultural feedstock and coproducts into poly(hydroxyalkanoates). Appl. Microbiol. Biotechnol., 71, 783-789.

Spiekermann, P.; Rehm, B.H.A.; Kalscheuer, R.; Baumeister, D. and Steinbuchel, A. (1999). A sensitive, viable-colony staining method using Nile red for direct screening of bacteria that accumulate polyhydroxyalkanoic acids and other lipid storage compounds. Arch. Microbiol., 171, 73-80.

Taweel, S.H.; Hohne, G.W.H.; Mansour, A.A. and Stolla, B. (2004). Glass transition and the rigid amorphous phase in semicrystalline blends of bacterial polyhydroxybutyrate PHB with low molecular mass atactic R, S-PHB-diol. Polymer 45, 983-992.
$\mathrm{Xu}, \mathrm{S}$; Luo, R.; Wu, L.; Xu, K. and Chen, G.-Q. (2006). Blending and Characterizations of Microbial Poly (3-hydroxybutyrate) with Dendrimers. J. Appl. Polym. Sci., 102, 3782-3790.

Yu, L.; Dean, K.. and Li, L. (2006). Polymer blends and composites from renewable resources. Prog. Polym. Sci., 31, 576-602.

Received: August 13, 2010; Revised: November 03, 2010; Accepted: March 14, 2011. 